\title{
O COSTUME NO ORDENAMENTO JURÍDICO BRASILEIRO COMO ELEMENTO DE MUTAÇÃO CONSTITUCIONAL
}

\author{
Giselle Marie Krepsky* \\ Thiago Cipriani*
}

\section{RESUMO}

Este artigo analisa a possibilidade de o costume constitucional servir como elemento de mutação constitucional, interpretando, integrando ou mesmo revogando a norma constitucional. Para tanto, utilizou-se o método indutivo e as técnicas bibliográficas e documentais. Utilizando-se como referencial teórico a doutrina constitucional contemporânea e da análise de casos concretos, conclui-se que há fundamentos para aplicação da mutação constitucional através do costume no ordenamento jurídico brasileiro, mas o tema está sujeito à interpretação e estabilização temática por meio das decisões dos tribunais sujeitas ao controle de constitucionalidade.

Palavras-chave: Constituição Federal; mutação constitucional; norma constitucional; costume jurídico; costume constitucional.

\section{THE CUSTOM IN BRAZILIAN LEGAL ORDERING AS AN ELEMENT OF CONSTITUTIONAL CHANGE}

\begin{abstract}
This article analyzes the possibility of constitutional custom serving as an element of constitutional change, interpreting, integrating or even revoking the constitutional norm. For this, the inductive method and bibliographic and documentary techniques were used. Using the contemporary constitutional doctrine as a theoretical framework and the analysis of concrete cases, it is concluded that there are grounds for applying constitutional mutation through custom in the Brazilian legal system, but the subject is subject to interpretation and thematic stabilization through court decisions subject to constitutionality control.
\end{abstract}

Keywords: Federal Constitution; constitutional mutation; constitucional norms; customary law; customary constitutional law.

\section{INTRODUÇÃO}

\footnotetext{
"Doutora em Direito pela Universidade do Vale do Rio dos Sinos (UNISINOS). Mestre em Educação (FURB). Professora do Programa de Mestrado em Direito da FURB. Líder do Grupo de Pesquisas CNPq/FURB: JUSTEC (Justiça, Educação e Ciência) e membro do Grupo de Pesquisas CNPq/FURB: Direitos Fundamentais, Cidadania e Justiça e Estado e Justiça e Constitucionalismo, Cooperação e Internacionalização - CONSTINTER.

** Mestrando em Direito pela Universidade Regional de Blumenau (FURB). Especialista em Direito Público: Constitucional e Administrativo (UNIVALI). Membro do Grupo de Pesquisas CNPq/FURB: JUSTEC (Justiça, Educação e Ciência) e membro do Grupo de Pesquisas CNPq/FURB: CONSTINTER (Constitucionalismo, Cooperação e Internacionalização). Advogado. E-mail: thiagoc@ furb.br.
} 
O costume ganha especial importância para o momento constitucional brasileiro, tendo em vista que a Constituição Federal de 1988 (CF) já tem mais de três décadas e algumas de suas normas se tornam obsoletas e descompassadas com a vida do cidadão. Trata-se de uma forma de atualizar a Constituição de acordo com a realidade, integrando as lacunas normativas e acolhendo os fatores reais do poder que regem as relações sociais, sem, contudo, alterar formalmente o texto (FERRAZ, 2015).

Assim, a pesquisa teve como objetivos a compreensão do costume constitucional diferenciando-o do costume jurídico sem status constitucional, identificar suas principais características, bem como esclarecer à luz da Doutrina constitucional contemporânea se a Constituição pode ser alterada a partir de processos informais, notadamente através do costume.

O artigo será desenvolvido a partir das linhas teóricas acerca do costume, tratará das suas características quando entendido como norma jurídica e das peculiaridades quando entendido como norma constitucional com o intuito de entender se há compatibilidade do costume com o sistema constitucional brasileiro.

É comum que os fatos da vida penetram no mundo jurídico, e os costumes ganham relevo de norma, assim o costume passa a ser um "hábito de comportamento generalizado com transcendência para o mundo do direito, capaz de gerar uma norma obrigatória para todos" (GARCIA CUADRADO, 2002, p. 280, tradução nossa).

Segundo Zagrebelsky (2005, p. 88), a constituição deve caminhar paralelamente à realidade social, fornecendo respostas adequadas aos problemas encontrados, de modo que a legitimidade da constituição não depende de quem a fez, mas "da capacidade de oferecer respostas adequadas ao nosso tempo ou, mais precisamente, da capacidade da ciência constitucional de buscar e encontrar essas respostas na constituição".

O conceito de mutação constitucional está associado à característica de permanência, possibilitando a alteração do sentido e do alcance das normas constitucionais sem necessariamente haver alteração do texto. A mutação constitucional não ocorre através de mecanismos constitucionalmente previstos, mas de uma mudança na realidade fática ou de uma nova percepção do Direito (BARROSO, 2019).

Por outro lado, há ainda quem defenda a possibilidade de alteração constitucional através de processos informais, o que surge do ambiente político ou através dos costumes, sem haver necessariamente alteração do texto escrito na Constituição (KUBLISCKAS, 2009). 
Buscou-se, portanto, elucidar se o costume constitucional é aceito no ordenamento jurídico brasileiro como processo de mutação constitucional e, a partir das bases teóricas eleitas, evidenciar as principais categorias em casos concretos nos quais o costume foi elevado a norma com status constitucional, seja com função integrativa, interpretativa ou além de verificar se é que é possível e admissível, substituição da norma constitucional formal. Apesar de não se tratar de estudo de caso, tomou-se como exemplo, algumas situações fáticas ocorridas para cotejar a perspectiva doutrinária e sua observação prática perscrutando, assim, os objetivos almejados.

\section{COSTUME JURÍDICO: CONCEITO E PRINCIPAIS LINHAS TEÓRICAS}

O ordenamento jurídico brasileiro, herdeiro do sistema romano-germânico, denominado também de Civil Law, tem como uma das principais características a codificação, o que lhe traz certa rigidez, com a exigência, pelo menos em tese, de um procedimento formal e complexo para ser alterado.

O Decreto-Lei $n^{\circ}$ 4.657/1942 (BRASIL, 1942), denominado inicialmente de Lei de Introdução ao Código Civil e atualmente de Lei de Introdução às Normas do Direito brasileiro, dispõe no artigo $2^{\circ}$ que a lei terá vigência até ser modificada ou revogada por outra lei. Em seu artigo $4^{\circ}$ dispõe que quando a lei for omissa, o julgador poderá se socorrer da analogia, dos costumes e dos princípios gerais do direito.

A partir dessas premissas, emerge a questão central do presente estudo, que é o entendimento do status do costume no sistema jurídico brasileiro. Preliminarmente, porém, é necessário entender que o costume, antes de ser jurídico, é um fato da vida, ou, conforme leciona Ferrara (1989, p. 47), “[...] é um ordenamento de fatos que as necessidades e as condições sociais desenvolvem e que, tornando-se geral e duradouro acaba impondo-se psicologicamente aos indivíduos.”

Quando o comportamento duradouro e psicologicamente imposto ao grupo social ingressa no ordenamento jurídico, seja pela decisão judicial, seja por meio dos órgãos administrativos do Estado, passa-se a ter um costume jurídico, e, em tese, obrigatório a todos.

Savigny, um dos precursores da escola histórica alemã, ensinava que o direito nasce do "espírito do povo", da consciência geral, não sendo possível desconsiderar o direito consuetudinário, já que este seria a verdadeira base do direito positivo. Veja-se: 
[...] examinando a verdadeira base de todo direito positivo, encontramos uma ordem de consequências e de princípios inteiramente diferentes. A base do direito positivo tem sua existência e sua realidade na consciência geral do povo. E esta consciência invisível de sua natureza, de onde a reconhecemos? Nos atos exteriores que a manifestam, nos usos, nos hábitos, nos costumes. (SAVIGNY, 1978, p. 410, tradução nossa).

Kelsen (1999, p. 157-158), em sua obra denominada de Teoria Pura do Direito, aceita o costume como um fato produtor do direito, destacando que o costume "só pode, porém, ser pensado como norma jurídica objetivamente válida se este fato assim qualificado e inserido na Constituição como fato produtor de normas jurídicas."

Portanto, para Kelsen, o costume até pode ser fonte do direito, contanto que assim esteja declarado na norma fundamental do ordenamento jurídico. Diferente do entendimento de Savigny, Kelsen defende que o "espírito do povo" não pode, por sua vontade ou por seu hábito, criar o direito, a menos que assim seja permitido pelo próprio ordenamento constituído.

A Constituição deve ser lida em sentido lógico-jurídico, tendo-se como "fato produtor do Direito não apenas o ato do autor da Constituição, mas também o costume constituído pela conduta dos indivíduos sujeitos à ordem jurídica constitucionalmente criada" (KELSEN, 1999, p. 157-158). Assim, o costume é válido, desde que a Constituição permita. Em semelhante pensamento, Bobbio (1995, p. 184) trata o costume como "uma autorização aos cidadãos para produzir normas jurídicas através do seu próprio comportamento uniforme", atribuindo-lhe a qualidade de fonte delegada.

Já para Zagrebelsky (1993, p. 259, apud LISBOA, 2012, p. 38), o pensamento kelsiano é insuficiente, defendendo que o direito, além de ser válido, deve ser eficaz, importando o critério de legitimidade compreendido como "coerência com o arranjo dos poderes que se manifestam e se estabilizam em um determinado contexto estatal."

Grau (2011, p. 44) defende que o legislador não é livre para criar o direito posto (direito positivo), estando condicionado pelo direito pressuposto, que "brota da (na) sociedade, à margem da vontade individual dos homens". No raciocínio do autor, "o direito pressuposto condiciona a elaboração do direito posto, mas este modifica o direito pressuposto." Ou seja, a manifestação da consciência do povo, inclusive por meio dos costumes, é de onde realmente nasce o direito. Conforme o pensamento do autor, é o direito 
pressuposto atuando como condicionante do direito posto. Assim, o princípio da efetividade serve de fundamento para as normas consuetudinárias, reconhecendo-a como materialmente integrante do ordenamento jurídico.

\section{CARACTERÍSTICAS DO COSTUME COMO NORMA JURÍDICA}

O costume jurídico possui algumas características marcantes, tratando-se de uma norma jurídica primária provida de valor jurídico e eficácia, cuja formação se dá de forma espontânea e voluntária, com caráter definitivo, mas que comporta modificação ou supressão, e vincula os órgãos do executivo e do judiciário (FERRAZ, 2015).

Vislumbra-se, pois, que a opinio necessitatis constitui elemento essencial do costume, ao lado do elemento material, tratando-se de um elemento psicológico, a expressão do consentimento dos sujeitos envolvidos no processo de sua elaboração. Entretanto, ausente um conceito bem definido e universalmente aceito, faz com que a maior parte da doutrina desconsidere tal elemento como essencial (LISBOA, 2012).

De maneira geral, o costume deve ser praticado por convicção, pressupondo-se a existência de "um ato de vontade individual ou coletivo cujo sentido subjetivo seja o deverser que é interpretado como norma objetivamente válida, como Direito consuetudinário." (KELSEN, 1999, p. 158).

Para Trevijano (1989, p. 45) o costume possui as seguintes características:

[...] pluralidade e repetição de comportamentos, uniformidade de comportamentos, continuidade, pluralidade de agentes, publicidade dos atos, racionalidade, certeza, veracidade dos atos, obrigatoriedade, liberdade dos atos, consentimento ou assentimento dos destinatários, transcurso do tempo e, por último, ânimo para induzir costume.

Há uma certa tendência em estabelecer como característica dos costumes a uniformidade de comportamentos repetidos por um conjunto de sujeitos, por determinado período, com a vontade de criar um padrão de comportamento que deverá ser seguido. Por óbvio não é necessário que todos tenham participado da criação do costume para torná-lo cogente, bastando a maioria dominante dos indivíduos. A exigência de unanimidade tornaria o costume ineficaz como ensejador de norma jurídica (KELSEN, 1999).

$\mathrm{Na}$ história dos ordenamentos jurídicos, quando considerada a relação entre leis e costumes, tem-se três situações: o costume sendo superior à lei; o costume e a lei situados no 
mesmo plano hierárquico; o costume sendo inferior à lei. Nesse contexto, pode-se dizer que o costume jurídico pode ser dividido em algumas categorias, quais sejam: secundum legem, praeter legem e contra legem. O costume secundum legem é previsto ou admitido pelo direito escrito, que determina sua observação em determinados casos, sendo também usado como elemento de interpretação do texto legal. O costume praeter legem, por sua vez, atua na função de preencher as lacunas do texto escrito, aparecendo quando a lei silenciar e se destaca como elemento interpretativo. Por último, o costume contra legem contraria a lei, opondo-se ao direito escrito, seja em razão do uso diverso do que dispõe a lei ou em razão do desuso do texto legal (FERRAZ, 2015).

Segundo Bobbio (1995, p. 168), o mais comum é encontrar situações em que a lei se encontra em plano hierarquicamente superior, inadmitindo-se os costumes contra legem, de modo que estes não teriam o condão de ab-rogar a lei. De acordo com o autor, o costume exerce "duas funções: a de Direito Subsidiário, para completar o Direito Escrito e lhe preencher as lacunas; e a de elemento de Hermenêutica, auxiliar da exegese" (MAXIMILIANO, 2017, p. 184).

São três as principais doutrinas que explicam o fundamento jurídico das normas consuetudinárias: a doutrina romano-canônica, a doutrina moderna e doutrina da escola histórica. Conforme explica Bobbio (1995, p. 166-167), "as duas primeiras negam ao costume o caráter de fonte de qualificação jurídica, visto que situam o fundamento da validade das normas consuetudinárias numa fonte diferente do próprio costume."

A doutrina romano-canônica equipara o costume à lei, já que ambos provêm da vontade do povo, tendo como única diferença a forma de expressão: no primeiro o povo exprime a vontade de forma expressa e no segundo de forma tácita (BOBBIO, 1995, p. 167).

A doutrina moderna, por sua vez, defende que as normas consuetudinárias, por serem criadas pela sociedade, não têm caráter jurídico, tornando-se jurídicas somente quando acolhidas pelo judiciário. A referida doutrina é criticada em dois pontos: um, se assim fosse não haveria costumes no direito público, especialmente no direito constitucional, pois não seria necessário que o judiciário atribuísse valor à norma; dois, e mais relevante, por esta teoria, os juízes não estariam obrigados a aplicar o costume, mas, em determinados ordenamentos o costume vincularia até mesmo o poder judiciário (BOBBIO, 1995, p. 167).

Finalmente, a escola histórica, que tem como um dos precursores Savigny, fundamenta a validade das normas consuetudinárias no próprio costume, outorgando-lhe 
caráter de fonte autônoma do direito. Para esta corrente, o costume tem caráter jurídico independente e desvinculado do legislador, do judiciário ou da ciência política, fundando-se tão somente na convicção jurídica popular (BOBBIO, 1995).

\section{COSTUME CONSTITUCIONAL: ENTRE A ATUALIZAÇÃO SOCIAL E A MUTAÇÃO}

A Constituição nasce do poder constituinte, que "só se faz inteligível à luz de considerações sobre o problema da legitimidade [...]" (BONAVIDES, 2011, p. 143), sendo somente o povo legitimado a estabelecer comandos à sociedade. Esse poder divide-se em político e jurídico, sendo o primeiro livre de limites formais, o próprio autor da Constituição, e o segundo, inserido na norma, responsável pela reforma do texto constitucional (BONAVIDES, 2011).

Segundo Barroso (2019, p. 131), o poder constituinte "é limitado pela cosmovisão da sociedade - suas concepções sobre ética, dignidade humana, justiça, igualdade, liberdade e pelas instituições jurídicas necessárias à sua positivação.” Estas concepções sociais, porém, são dinâmicas e mutáveis, de modo que a Constituição, além de manter a ordem jurídica estabelecida pelo constituinte, precisa ser dotada de certo grau de flexibilidade, com o objetivo de manter-se atual aos anseios do povo (BARROSO, 2019, p. 132).

A Constituição é dotada de um elemento dinâmico e outro estático. O primeiro refere-se a um comportamento para mudanças informais e outorga estabilidade às normas que constituem a estrutura do Estado. Nesse sentido, a inalterabilidade da Constituição é relativa, podendo sofrer alterações mesmo sem as formalidades previstas no próprio texto, o que é denominado de mutação constitucional (BULOS, 1996). Para Bulos (1996), o fenômeno da mutação constitucional ocorre a partir de interpretação, jurisprudência, costumes, alterações legislativas, práticas políticas, pressão e influência da sociedade civil. Aliás, é nesse tocante que Barroso (2019, p.150) explica que "a mutação constitucional em razão de uma nova percepção do Direito ocorrerá quando se alterarem os valores de determinada sociedade. A ideia do bem, do justo, do ético varia com o tempo".

Porém, é preciso considerar que essa atualização do mundo da vida, das transformações sociais se faz ou pela alteração formal da Constituição (neste caso pelo Legislativo) ou pela mutação constitucional. Como bem explica Streck (2017) na primeira 
opção há uma explícita alteração do texto da Constituição ou o texto da norma constitucional. Por outro lado, a mutação atua exatamente no campo da interpretação/aplicação deste texto que resulta na alteração da norma contida neste mesmo texto. Tais situações comportam a atualização necessária ao direito posto e escrito. Isso não quer dizer que o resultado de uma interpretação mais adequada ao contexto social permita uma alteração do próprio texto quando a aplicação dele ao caso concreto faria externalizar norma cujo sentido extrapolaria os contornos textuais.

É indissociável ao tema costume constitucional o estudo das fontes materiais ou extra ordinem. No direito, tal como sedimentando em nossa cultura jurídica, as fontes formais ganham maior relevância. Contudo, em se tratando de direito constitucional, o pensamento é inverso, tendo em vista que os elementos da realidade "que dão causa à elaboração de uma norma têm importância capital, pois podem ocasionar a própria substituição de uma constituição por outra" (LISBOA, 2012, p. 42).

Nesse sentido, Lassalle (2001, p. 33), buscando explicar “Que é uma constituição?”, esvazia o seu significado formal, dizendo que, despida da realidade que está à sua volta, a constituição não passa de uma "folha de papel". O autor pergunta: "quando podemos dizer que uma constituição escrita é boa e duradoura?" Ele mesmo responde: “quando essa constituição escrita corresponder à constituição real e tiver suas raízes nos fatores do poder que regem o país".

Na mesma linha, Hesse (1991, p. 7), leciona que a "norma constitucional não tem existência autônoma em face da realidade. A sua essência reside na sua vigência, ou seja, a situação por ela regulada pretende ser concretizada na realidade.” Essa ideia pode conduzir ao entendimento de que o pensamento kelsiano é inacabado, insuficiente para justificar a validade de uma norma, tendo em vista que, para Lassalle e para Hesse, o direito precisa ser eficaz, sob pena de não alcançar seu fim último: a pacificação social.

Sempre que a Constituição não corresponder à realidade posta, haverá uma ruptura, uma revolução, que poderá acarretar o aprimoramento na norma constitucional ou, dependendo da relevância, no surgimento de uma nova ordem jurídica. Em um sistema constitucional baseado na Common Law, a Constituição é construída a partir da realidade, dos fatos, das convenções dos costumes etc. Por outro lado, em um sistema constitucional escrito e rígido, há certa resistência em aceitar processos informais de mutação constitucional. Logo, a análise do costume constitucional no sistema jurídico brasileiro, inevitavelmente precisa 
enfrentar a pergunta formulada por Ferraz (2015, p. 183): "seria incompatível o costume constitucional com a noção de constituição formal, rígida e escrita?", a depender da linha teórica escolhida, existirão diferentes respostas.

De acordo com Burdeau (1969, p. 288, apud FERRAZ, 2015, p. 183), parte da doutrina não admite a validade de costumes constitucionais em ordenamento jurídico de constituição rígida, defendendo que, nessa hipótese, "não há lugar para costume, seja criativo, modificador, supletivo ou simplesmente interpretativo da constituição, pois toda norma, inclusive a não escrita, cede diante da superioridade da norma constitucional".

Há quem defenda que a norma consuetudinária tem ação subsidiária e, portanto, sem poder de ab-rogar o texto escrito. Seria, portanto, aceito o costume secundum Constitutionem, em caso de lacuna da norma, e praeter constitutionem, com função de integração da norma (DAL RI, 2016). Neste pensamento, o poder constituinte difuso deve continuar a obra do constituinte originário, preenchendo os vazios e encontrando fundamento, ainda que implícito, na lei fundamental. Trata-se de decorrência lógica da constituição, mas que é naturalmente limitada, tendo sua atuação restrita a "precisar ou modificar o sentido, o significado e o alcance, sem, todavia, vulnerar a letra constitucional" (FERRAZ, 2015, p. 10).

Pode-se citar ainda uma terceira corrente, para a qual, o costume constitui espécie de norma constitucional que se origina de fatos e não da autuação legislativa, razão pela qual poderia, inclusive, alterar a Constituição. Nesta senda, para justificar a existência de normas constitucionais não escritas, cita-se o direito supraconstitucional, que fundamenta o poder, o funcionamento do aparato estatal e até mesmo a elaboração da Constituição (LISBOA, 2012). Aderindo a esta terceira corrente, Burdeau (1969, p. 246-247, apud FERRAZ, 2015, p. 10), defende que as alterações constitucionais:

[...] operadas fora das modalidades organizadas de exercício do poder constituinte instituído ou derivado, justificam-se e têm fundamento jurídico: são, na realidade, obra e manifestação de uma espécie organizada do Poder Constituinte, o chamado poder constituinte difuso [...].

No Brasil é mais recorrente encontrar a possibilidade do costume como prática de interpretação e integração constitucional, sendo bastante controversa a adoção de costumes contrários a constituição, de modo que "o costume tem o condão de alterar o alcance, significado e sentido da Constituição, preservando-lhe o texto" (AMORIN, 2014, p. 247). 
Sobre a aplicação do costume no processo de mutação constitucional, Bobbio (2003, p. 36), utilizando-se de um pensamento bastante prático, defende que o que vai definir o costume como jurídico é o fato de ter sua validade chancelada pelos órgãos do poder. Veja-se:

\begin{abstract}
Mas a esta objeção se pode responder que nenhum costume se torna jurídico só através do uso, porque o que o faz tornar-se jurídico, o que o insere no sistema, é o fato de ser acolhido e reconhecido pelos órgãos competentes desse sistema para produzir normas jurídicas, como o legislador ou o juiz. Enquanto for apenas eficaz, uma norma consuetudinária não se torna jurídica. Transforma-se em jurídica quando os órgãos de poder lhe atribuem validade, o que confirma que a eficácia não se transforma diretamente em validade, e, portanto uma norma pode continuar a ser eficaz sem por isso se tornar jurídica. (BOBBIO, 2003, p. 36)
\end{abstract}

Verifica-se a existência maior de casos de costumes constitucionais naquilo que a doutrina convencionou chamar de práticas administrativas. Apesar da existência de norma constitucionais e infraconstitucionais tratando do funcionamento da administração pública, sua estrutura complexa costuma reger-se por práticas convencionais. Muito embora não escritas, sua perpetração temporal atribui-lhes o caráter de obrigatórias (AMORIN, 2014).

Streck (2004, p. 131, apud ROSA, p. 127, 2020), chama atenção para a existência de limites para a mutação constitucional, afirmando que o intérprete não pode atuar de forma discricionária e indiscriminada, de modo a não atribuir sentidos arbitrários à norma, o que poderia desfigurar a Constituição. Assim, se seguir o pensamento de Bobbio (2003, p. 36), de que o costume ganha status de norma quando tiver sua validade chancelada pelos órgãos do poder, é imprescindível que esta chancela não seja arbitrária, respeitando os limites para não criar uma norma de existência autônoma da própria Constituição.

Como forma de controlar medidas arbitrárias, o direito norte-americano possui um eficaz sistema de freios e contrapesos, exercido através das regras de reserva institucional e de tolerância mútua. A maioria dessas regras não estavam escritas, mas originaram-se de convenções que se reiteraram no tempo, resultando na garantia da democracia mesmo em situações adversas. Cita-se trecho do livro que resume a importância dessas regras não escritas para o fortalecimento da Democracia:

Na virada do século $X X$, então, as normas de tolerância mútua e reserva institucional estavam bem estabelecidas. Com efeito, elas se tornaram a fundação do nosso muito admirado sistema de freios e contrapesos. Para que o sistema constitucional funcione como esperamos que funcione, $o$ 
Executivo, o Congresso e o Judiciário têm que encontrar um equilíbrio delicado. Por um lado, o Congresso e os tribunais precisam supervisionaria e, quando necessário, frear o poder do presidente. Eles têm que ser cães de guarda da democracia. Por outro lado, o Congresso e os tribunais devem permitir que o governo opere. É aí que a reserva entra em cena. Para que a democracia presidencial tenha êxito, instituições fortes o bastante para frear o presidente têm que subutilizar este poder. (LEVITSKY; ZIBLATT, 2018, p. 124)

No Brasil, doutrina e jurisprudência não encontraram unanimidade quanto à existência, validade e alcance do costume constitucional. Entretanto, pode-se dizer que se tem praticado vários costumes constitucionais, inclusive afrontando o texto constitucional, o que faz parecer que o pensamento de Bobbio serve muito bem ao ordenamento brasileiro, de modo que é mais crível a ideia de que a validade e eficácia do costume ficarão adstritas a chancela dos órgãos do poder.

\section{CASOS CONCRETOS EM QUE O COSTUME FOI ALÇADO AO STATUS DE NORMA CONSTITUCIONAL}

Diante da revisão bibliográfica lançada nas linhas alhures, tem-se que o costume surge como elemento de mutação constitucional, sendo, ao menos em tese, aplicável com a finalidade de integrar e interpretar a Constituição, restando a possibilidade de revogá-la mais controversa e questionável (FERRAZ, 2015).

Barroso (2019, p. 149-150), analisando o tema mutação constitucional por via de costume, lança alguns exemplos, destacando a implantação do sistema parlamentar durante o segundo Reinado, quando o Poder Executivo foi compartilhado pelo Imperador e pelo Gabinete de Ministros, mesmo sem haver qualquer norma escrita que autorizasse a prática. Menciona também um costume atual, que expandiu os poderes das Comissões Parlamentares de Inquérito (CPI), passando a admitir a quebra de sigilo bancário, telefônico e físcal dos investigados, mesmo à revelia de norma escrita autorizativa.

Discordando da possiblidade de costume contrário a constituição, Barroso (2019, p. 149) lembra que no ano de 2005 foi rejeitada, por ato administrativo confirmado pelo Poder Judiciário, a prática de nomeação de parentes de juízes para atuar em cargos que independiam de concurso, o que figura nepotismo. 
Em pesquisa jurisprudencial realizada no Supremo Tribunal Federal (STF) pelo exato termo "costume constitucional", encontrou-se dois acórdãos. Trata-se de decisões na Ação direta de Inconstitucionalidade número 644 e no Agravo Regimental contra decisão monocrática em Mandado de Segurança de número 31818.

A Ação Direta de Inconstitucionalidade número 644 (BRASIL, 1992), de relatoria do Ministro Sepúlveda Pertence, foi ajuizada pelo Procurador-Geral da República em face de ato normativo expedido pelo Governador do Estado do Amapá, que limitava o Vice-Governador a assumir o cargo nos casos de moléstia, licença ou férias, e de ausência do estado por prazo superior a 15 (quinze) dias.

Até então a Constituição Estadual não havia sido promulgada. O STF decidiu que o estado não deveria seguir lei ordinária local ou decreto executivo, mas o padrão federal similar, onde a substituição se daria pelo Vice-Presidente. Ocorre que a Constituição Federal “jamais definiu os impedimentos do Presidente da República, pressuposto de sua substituição temporária pelo Vice-Presidente", mas, em razão de uma prática constitucional estabelecida desde o Império, a substituição do chefe do Poder Executivo se daria pelo respectivo vice (BRASIL, 1992).

Assim, reconhecendo inexistir norma constitucional formal, o STF entendeu que, por costume constitucional federal que determinava que nos impedimentos do Presidente o governo era assumido pelo Vice-Presidente, o governo estadual deveria seguir a mesma regra, de modo que a chefia do executivo deveria ser assumida pelo Vice-Governador nos impedimentos ou ausências temporárias do Governador.

No Mandado de Segurança de número 31818 (BRASIL, 2013), analisa-se o acórdão em agravo regimental interposto pela Mesa do Congresso Nacional em face de decisão monocrática que deferiu liminar para, diante da existência de fumus boni iuris e periculum in mora, declarar inconstitucional a prática do Congresso Nacional de apreciar aleatoriamente os vetos presidenciais, entendendo imprescindível a deliberação acerca dos vetos respeitando uma ordem cronológica.

Após requerimento da União para afetação do processo ao Plenário do Supremo Tribunal Federal, foi dado provimento ao agravo regimental, vencidos os Ministros Luiz Fux, Marco Aurélio, Celso de Mello e Joaquim Barbosa, para revogar a decisão liminar que ordenava ao Congresso Nacional a observância à ordem cronológica na apreciação dos vetos presidenciais. 
O redator do acórdão, Ministro Teori Zavascki, reconheceu que seria pouco provável o reconhecimento da inconstitucionalidade da prática do Congresso Nacional quando do julgamento definitivo da matéria. O Ministro Gilmar Mendes, em seu voto, utilizou a expressão "costume constitucional" e afirmou que a prática de não observância da ordem cronológica se sedimentou em razão de um tipo de concordância mais ou menos geral.

Portanto, na oportunidade o entendimento foi de que a liminar deveria ser revogada e mantida a prática do Congresso Nacional em analisar os vetos sem respeitar a ordem cronológica. Por fim, o Mandado de Segurança foi extinto por perda superveniente do objeto, uma vez que o Congresso Nacional rejeitou o veto aposto pelo Presidente da República e houve promulgação das partes originalmente vetadas.

Mais recentemente, em que pese o caso não ter sido submetido à apreciação do STF, houve debate acerca da existência ou não de costume constitucional na escolha do Procurador-Geral da República pelo Presidente da República. Desde o ano de 2003, o Procurador-Geral da República é escolhido pelo chefe do poder executivo a partir de lista tríplice formada através de votação organizada pela Associação Nacional dos Procuradores da República. A partir de então todos os presidentes da República acataram a referida lista tríplice, assegurando a indicação democrática e independente do Procurador-Geral da República, fato este que, para muitos, passou a ter status de norma, constituindo um costume constitucional. Entretanto, o atual presidente da República, Jair Messias Bolsonaro, ignorou a lista tríplice composta por Mário Bonsaglia, Luiza Frischeisen e Blal Dalloul, e indicou Antônio Augusto Brandão de Aras para o cargo, o qual foi aprovado pelo Senado Federal (ASSOCIAÇÃO NACIONAL DOS PROCURADORES DA REPÚBLICA, 2019).

Segundo Nunes (2019), a escolha do Procurador-Geral da República por meio da lista tríplice respeitaria a democracia interna do Ministério Público, a independência do escolhido e o princípio republicano, tendo em vista que o Procurador-Geral teria um mandato temporário, legitimidade decorrente da eleição e ficaria vinculado a prestar contas acerca dos compromissos de campanha. Para Aras (2018), desde ano de 2003:

[...] as listas tríplices para PGR vêm sendo respeitadas pelos sucessivos presidentes da República. Evidentemente, os escolhidos têm sido selecionados dentre os membros do MPF, observando-se o $\$ 1^{\circ}$ do art. 128 da CF. É seguro dizer, portanto, que já se constituiu ou se está em vias de constituir um costume constitucional para sua observância, costume este que 
resulta da reiteração do comportamento dos órgãos de soberania competentes, isto é, a presidência da República e o Senado Federal.

A indicação não foi bem recebida pela ANPR que, em nota, classificou a indicação como escolha pessoal do Presidente da República, decorrente de afinidade de pensamento, com menosprezo aos princípios fundamentais que alicerçam a instituição Ministério Público (ANPR, 2019).

Entretanto, até o momento nenhuma medida efetiva foi tomada, e a resposta para essa questão somente virá mediante a provocação de órgãos oficiais para que se manifestem sobre a constitucionalidade do ato do Presidente da República ou pelo resgate do costume por futuros chefes do Poder Executivo.

\section{CONSIDERAÇÕES FINAIS}

A presente pesquisa foi elaborada com o objetivo de entender se os costumes constitucionais são compatíveis com o sistema jurídico brasileiro, e, para dar um contorno prático e atual à problemática eleita, foram analisados três casos. Os dois primeiros foram extraídos de decisões do STF e o terceiro caso não foi submetido ao judiciário, mas foi veiculado na mídia como suposta afronta a costume constitucional.

Para a adequada compreensão do tema, estudou-se inicialmente o costume jurídico em si, seu conceito e principais linhas teóricas, o que permitiu entender que o costume jurídico é um fato da vida que, por sua relevância e dimensionamento outorgado por determinada sociedade, ingressa no mundo jurídico, tornando-se obrigatório a todos, com força de lei escrita.

A mais relevante das controvérsias que surgem quando se estuda as características do costume é sua posição em relação à lei, podendo ser classificado como secundum legem, praeter legem e contra legem. Isto é, o costume pode ser "segundo a lei", quando é previsto pela norma escrita, com a função de interpretar o direito escrito; a segunda categoria designa os costumes não previstos pela norma, mas que complementam o direito escrito; e a terceira e mais controversa das categorias, o costume "contra a lei", que se opõe ao direito escrito. 
Indubitavelmente são mais facilmente aceitos os costumes secundum legem e praeter legem, havendo resistência aos costumes contra legem em sistemas jurídicos como o do Brasil, derivados da Civil Law.

A partir dessas premissas é possível ingressar propriamente no tema e lançar as principais considerações sobre costumes constitucionais no ordenamento jurídico brasileiro. $\mathrm{O}$ primeiro ponto que merece destaque e que parece atestar a existência de costumes constitucionais é o reconhecimento acerca da existência de fontes materiais dissociadas de fontes formais no direito constitucional. Há relevante parte da Doutrina que entende que a Constituição não pode ser representada somente por normas escritas, sendo imprescindível a construção do sistema a partir da "realidade das ruas" ou dos fatores reais do Poder. Não é facilmente encontrado posicionamento que negue a existência do costume constitucional, mas, por outro lado, há ávido debate acerca da posição do costume: se meramente subsidiário ou se possui poder de ab-rogar a norma constitucional escrita.

Colacionou-se no corpo da pesquisa interessante conclusão de Norberto Bobbio, para quem a existência e eficácia do costume constitucional está diretamente ligada à chancela dos órgãos do Poder. No Brasil, por exemplo, a existência e o efeito do costume estão diretamente ligados ao seu acolhimento pelo Judiciário, principalmente através do STF, guardião máximo da Constituição Federal.

Essa ideia ganha relevo quando dá análise dos exemplos trazidos. Nos casos analisados pelo STF, os costumes foram reconhecidos e fundamentaram a decisão, já do caso que não foi deliberado pela corte, o ato do poder executivo foi contrário ao alegado costume e permanece vigente.

Portanto, interessante para o escopo da pesquisa é que a constatação desses recortes fáticos eleitos atesta a conclusão de Norberto Bobbio, para quem o mero uso do costume não o torna jurídico, sendo imprescindível o acolhimento do mesmo pelos órgãos oficiais, como é o legislador ou o julgador.

Ademais, destaca-se que, ainda que haja a recepção do costume como forma de atualização da norma contida no texto constitucional porquanto necessária à sua própria aplicação, ela não deve extrapolar o sentido de modo a alterar seu próprio texto, cuja função seria do legislativo sujeita ao controle de constitucionalidade. E mais, ainda que se admita a corrente pautada em Bobbio de que a incorporação do costume na seara constitucional, sobretudo, só se perfectibiliza a partir da chancela decisória judicial, tal chancela não pode 
exceder, igualmente, os limites da interpretação e sentidos que se podem dar ao texto constitucional, sob pena de realizar-se muito mais do que a mera adequação do texto à vida cotidiana.

\section{REFERÊNCIAS}

AMORIN, Pedro Rocha. Mutação constitucional: conceito, espécies e limites. Brasília a. 33 n. $129 \quad$ jan./mar. $1996 . \quad$ Disponível $\quad$ em https://www.fdsm.edu.br/adm/artigos/7f4a4ed029d6b7c1b6ed9e5c5268e1ab.pdf. Acesso em 3 abr. 2021.

ARAS, Vladimir. A origem da lista tríplice para a escolha dos Chefes do Ministério Público. Disponível em https://vladimiraras.blog/2018/10/12/a-origem-da-lista-triplice-paraa-escolha-dos-chefes-do-ministerio-publico. Acesso em: 2 abr. 2021.

ASSOCIAÇÃO NACIONAL DE PROCURADORES DA REPÚBLICA. Nota pública: Desrespeito à lista tríplice é o maior retrocesso democrático e institucional do MPF em 20 anos. Disponível em: https://www.anpr.org.br/imprensa/releases/18196-nota-publica-desrespeito-\% $3 \%$ A0-lista-triplice-e-o-maior-retrocesso-democratico-e-institucional-do-mpfem-20-anos. Acesso em: 2 abr. 2021.

ASSOCIAÇÃO NACIONAL DE PROCURADORES DA REPÚBLICA. Lista Tríplice para PGR. Disponível em: https://www.anpr.org.br/institucional/lista-triplice Acesso em: 2 abr. 2021.

BARROSO, Luís Roberto. Curso de direito constitucional contemporâneo: os conceitos fundamentais e a construção do novo modelo. 9. ed. São Paulo: Saraiva, 2019.

BRASIL, Decreto - Lei $n^{0}$. 4.657, de 4 de setembro de 1942 - Lei de Introdução às Normas do Direito Brasileiro. Disponível em: http://www.planalto.gov.br/ccivil_03/decretolei/Del4657compilado.htm, último acesso em 3 abr. 2021.

BRASIL. Constituição (1988). Constituição da República Federativa do Brasil. Brasília, DF: Senado Federal: Centro Gráfico, 1988.

BRASIL. Supremo Tribunal Federal. Ação Direta de Inconstitucionalidade: ADI644 MC. Relator: Ministro Sepúlveda Pertence. Julgamento em 04/12/1991. Publicação em 21/02/1992. Disponível em: https://jurisprudencia.stf.jus.br/pages/search/sjur116624/false. Acesso em 4 abr. 2021.

BRASIL. Supremo Tribunal Federal. Agravo Regimental em Mandado de Segurança: MS3118 MCAgr. Relator: Ministro Luiz Fux. Redator: Teori Zavascki. Julgamento em 07/02/2013. Publicação em 13/05/2013. Disponível em: https://jurisprudencia.stf.jus.br/pages/search/sjur230054/false. Acesso em: 4 abr. 2021. 
BOBBIO, Norberto. O positivismo jurídico: lições de filosofia do direito. São Paulo: Ícone, 1995.

BOBBIO, Norberto. Teoria da norma jurídica. 2. ed. São Paulo: Edipro, 2003.

BOBBIO, Norberto. Teoria do ordenamento jurídico: apresentação Tércio Sampaio Ferraz Júnior, trad. Maria Celeste C. J. Santos; rev. téc. Cláudio De Cicco. $6^{\mathrm{a}}$ ed. Brasília: Editora Universidade de Brasília, 1995.

BONAVIDES, Paulo. Curso de Direito Constitucional. 26. ed. São Paulo: Malheiros, 2011.

BULOS, Uadi Lamêgo. Da reforma à mutação constitucional. Brasília a. 33 n. 129 jan./mar. 1996. Disponível em: https://www2.senado.leg.br/bdsf/bitstream/handle/id/ 176380/000506397.pdf?sequence=1\&isAllowed=y. Acesso em 3 abr. 2021.

DAL RI, Luciene. O Costume como fonte do direito: entre o constitucional e o internacional. In: Maurizio Oliviero; Pedro Manoel Abreu; Liton Lanes Pilau Sobrinho;Rafael Padilha dos Santos Luciene Dal Ri Orlando Luiz Zanon Jr. (Org.). CONSTITUCIONALISMO COMO ELEMENTO PARA A PRODUÇÃO DO DIREITO. 1ed. v.1. Itajaí: Univali, 2016.

FERRARA. Freitas Bastos. Introdução à Ciência do Direito. Rio de Janeiro: Biblioteca Freitas Bastos, 1989.

FERRAZ, Anna Cândida da Cunha. Processos informais de mudança da constituição: mutações constitucionais e mutações inconstitucionais. 2. ed. Osasco: EdiFIEO, 2015.

GARCIA CUADRADO. Antonio M. El ordenamiento constitucional. Un enfoque histórico y formal de la teoría de la constitución y de las fuentes del derecho. Alicante: Editorial Club Universitario, 2002.

GRAU, Eros Roberto. O Direito posto e o Direito pressuposto. 8. ed. São Paulo: Malheiros, 2011.

HESSE, Konrad. A força normativa da constituição. Trad. Gilmar Ferreira Mendes. Porto Alegre: Sergio Antônio Fabris. 1991.

KELSEN, Hans. Teoria pura do direito. São Paulo: Martins Fontes, 1999.

KUBLISCKAS, Wellington Márcio. Emendas e mutações constitucionais: análise dos mecanismos de alteração formal e informal da Constituição Federal de 1988. São Paulo: Atlas, 2009.

LASSALlE, Ferdinand. A Essência da Constituição. 6. ed. Rio de Janeiro: Lumen Juris, 2001.

LEVITSKY, Steven; ZIBLATT, Daniel. Como as democracias morrem. 1. ed. Rio de Janeiro: Zahar, 2018.

Revista Brasileira de Teoria Constitucional | e-ISSN: 2525-961X | Encontro Virtual | v. 7 | n. 1 |

p. $90-107$ | Jan/Jul. 2021. 
LISBOA, Carolina Cardoso Guimarães. Normas constitucionais não escritas: costumes e convenções da constituição. 2012. 243 f. Tese (Doutorado em Direito) - Faculdade de Direito da USP, São Paulo. 2012.

MAXIMILIANO, Carlos. Hermenêutica e aplicação do direito. 21. ed. Rio de Janeiro: Forense, 2017.

NUNES, Leandro Bastos. A importância da lista tríplice para assegurar a independência da PGR. Consultor Jurídico. Disponível em: https://www.conjur.com.br/2019-mai24/leandro-nunes-lista-triplice-asseguraindependencia-pgr. Acesso em: 2 abr. 2021.

ROSA, Gilmar Madalozzo da. Mutação Constitucional: limites e possibilidades. Programa de Direito Constitucional, Fortaleza, 2020. Disponível em: https://uol.unifor.br/ oul/conteudosite/F86027120201124143836280335/Tese.pdf. Acesso em: 3 abr. 2021.

SAVIGNY, Fridrich Carl von. Sistema del derecho romano actual. Madri: F. Góngora Y Compañia, Editores, 1879.

STRECK, LENIO LUIZ. Verdade e consenso: Constituição, hermenêutica e teorias discursivas. 6.ed. São Paulo: Saraiva, 2017.

TREVIJANO, Pedro José G. La costumbre en Derecho constitucional. Madrid: Congreso Diputados, 1989.

ZAGREBELSKY, Gustavo. Historia y constitución. Trad. e prólogo de Miguel Carbonell. Madri: Trotta, 2005. 